$p$-ISSN 1693-9484, $e$-ISSN : 2621-8313

Majalah Ilmiah Bahari Jogja (MIBJ)

Vol. 17 No. 1, Februari 2019 (20-36)

DOI : $10.33489 /$ mibj.v17i1.197

(C) 2019 Akademi Maritim Yogyakarta

\title{
Penciptaan Nilai Logistik Pelabuhan di Indonesia
}

\author{
Cahya Purnomo ${ }^{1 *}$, Suyanti ${ }^{2}$ \\ ${ }^{1,2}$ Akademi Maritim Yogyakarta, Jl. Magelang KM. 4,4, Yogyakarta 55284 Indonesia \\ *Corresponding Author. E-mail: cahyapiyungan@gmail.com. Telp. +6281802743861
}

\begin{abstract}
Abstrak
Tulisan ini menyoroti penciptaan nilai logistik di pelabuhan Indonesia, dengan metode me-review jurnal-jurnal yang membahas penciptaan nilai logistik. Temuannya bahwa logistik pelabuhan di Indonesia menghadapi masalah berupa kebijakan, infrastruktur transportasi, ketersediaan barang, sumberdaya penyedia jasa logistik. Nilai logistik di pelabuhan ada 3 (tiga), yaitu berseri, dikumpulkan lebih dulu, dan timbal-balik. Kegiatan masing - masing pelaku di pelabuhan semakin terintegrasi semakin baik. Belum sinkronnya aliran barang yang masuk ke pelabuhan dengan yang keluar.
\end{abstract}

Kata kunci: Nilai logistik pelabuhan

\begin{abstract}
This paper highlights the creation of Indonesian ports logistics value, by review relevance journals. The finding are taht Indonesian ports faces problems, i.e policy concern to national logistics, transportation's infrastructure, availability of cargo, skill concern logistics. There are 3 (three) port logistics value : serial activity, pooled activity, and reciprocal activity. The activities of each actor in the port are getting better and better integrated. While there is no synchronization of flow of goods that enter and exit of the port.
\end{abstract}

Key words: Port logistics value

\section{PENDAHULUAN}

Hubungan antar negara memerankan pelabuhan sebagai pintu gerbang keluar-masuk barang-barang yang diperdagangkan (Song and Panayides, 2008). Industri pelayaran yang di dalamnya ada bisnis pelabuhan merupakan industri yang paling mendunia (Greenwood and Hanson, 2015). Perubahan utama dalam sistim perdagangan dipengaruhi oleh industri pelayaran. Pelabuhan kini dituntut untuk lebih mengintegrasikan aktivitas-aktivitas di dalamnya agar logistik efektif dan efisien (Notteboom and Rodrigue, 2005; Ferrari and Parolla at al, 2006).

Pelabuhan berperan signifikan dalam mengkoordinasikan barang karena pelabuhan merupakan simpul transportasi, dan transportasi sendiri merupakan bagian dari mata rantai pasok secara keseluruhan (Radhika, 2012). Menurut Song and Panayides (2008), pengembangan transportasi sekarang harus menempatkan pelabuhan sebagai konteks sistim matarantai pasok global yang terintegrasi. Pelabuhan telah menjadi elemen rantai pasok global yang dikontrol oleh entitas logistik, yaitu perusahaan pelayaran, freight forwarder serta operator transportasi (Rodrigue and Browne, 2010), agar berkinerja baik. Syarat kinerja pelabuhan yang 
baik adalah kemampuan bersaing melalui cargo handling di samping konektivitas dalam mata rantai pasok secara keseluruhan. Faktanya jenis entitas logistik di setiap pelabuhan berbeda-beda, koordinasi di antara mereka sulit (Hakansson and Persson, 2004). Peran pelabuhan berperan signifikan dalam logistik atau mata rantai pasok (Lambert et al, 1998).

Menurut Robinson (2002), pelabuhan sebagai tempat kapal memindahkan muatan / penumpang dari dan ke kapal dan daratan. Di pelabuhan merupakan simpul jaringan transportasi dalam rangka pergerakan barang. Kegiatan pergerakan barang ketika berlangsung kegiatan bongkar-muat dari dan ke kapal, terjadi perpindahan moda transportasi dari kapal ke truk atau sebaliknya atau tempat terjadinya pertemuan inter-moda transportasi (Radhika, 2012). Interdepensi di antara pelaku di pelabuhan menciptakan pergerakan barang. Merujuk bahwa esensi logistik adalah pergerakan barang dan informasi secara efektif (Christopher, 2011). maka jelas di pelabuhan terjadi kegiatan logistik. Pergerakan barang di pelabuhan memerlukan aliran yang smooth agar kinerja logistik meningkat. Bank Dunia (2014), melaporkan bahwa indeks logistik Indonesia pada urutan 53 sementara Vietnam pada tingkat 48 dari 160 negara yang disurvey, satu posisi yang rendah. Salah satu penyebabnya adalah aliran barang yang terjadi di pelabuhan yang tidak smooth. Bahwa pergerakan barang di pelabuhan merupakan awal dari logistik nasional. Pergerakan barang di pelabuhan lancar berarti meningkatkan kinerja logistik nasional, karena di pelabuhan merupakan penopang logistik nasuional.

Robinson (2002), memberikan gagasan bahwa di pelabuhan terjadi penciptaan nilai dari pergerakan barang yang dibentuk oleh pelaku-pelaku yang terlibat di dalamya. Interdependensi di antara mereka menciptakan nilai logistik, baik yang dinikmati oleh mereka sendiri (sebagai konsumen antara) maupun oleh konsumen akhir (Lambert et al, 1998).

Di pelabuhan terjadi hubungan upstream yaitu dengan pengirim barang dan sekaligus hubungan down stream dengan penerima barang ketika barang keluar pelabuhan (Vitsounis and Pallis, 2012). Dalam masing-masing hubungan itu diciptakan nilai logistik yang dinikmati oleh pelaku aktivitas di pelabuhan. Nilai logistik di pelabuhan adalah penerimaan barang secara efisien dan efektif (Lee and Song, 2010), bagi konsumennya. Menurut Carbone and DeMartino (2003), pelabuhan adalah entitas yang terlibat dalam menghantarkan nilai ke konsumen akhir.

Selama dekade terakhir telah terjadi 3 (tiga) kecenderungan dalam pengembangan logistik, yaitu semakin terintegrasi, semakin terspesialisasi, dan inovasi (Hakansson and Persson, 2004). Tujuannya adalah menurunkan biaya (biaya persediaan bahan), biaya handling barang, serta menurunkan throughput time. Oleh karenanya isu ini memerlukan koordinasi semakin rapat di antara pemangku kepentingan di pelabuhan. Secara umum kondisi sistem logistik di pelabuhan Indonesia saat ini belum memiliki kesatuan visi yang mampu mendukung peningkatan daya saing pelaku bisnis, kegiatan logistik relatif masih bersifat parsial dan sektoral di masing-masing lembaga terkait, sementara koordinasi yang ada belum memadai. Perhatikan gambar unsur-unsur logistik Indonesia yang bentuknya belum sesuai untuk berputar agar mekanisme logistik berjalan (baik). 


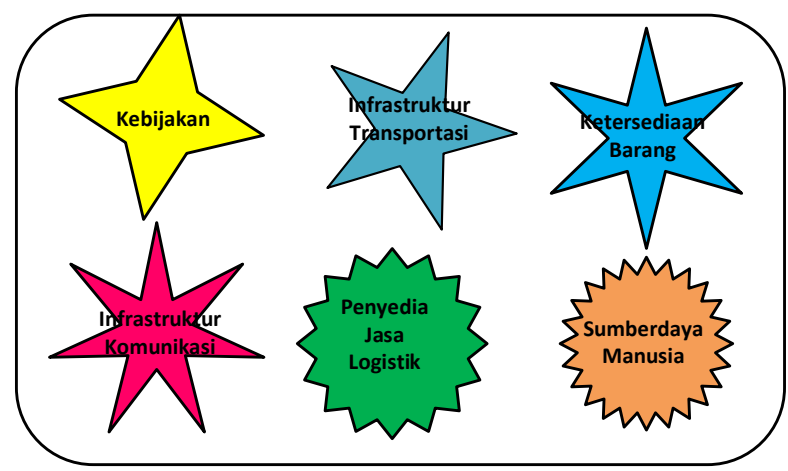

Gambar 1. Kondisi Logistik Nasional

Sumber: Perpres No. 26/2012, dengan penyesuaian

Masalah tersebut terdiri dari :

1) Komoditas penggerak utama (key commodity factor) sebagai penggerak aktivitas logistik belum terkoordinasi secara efektif, belum adanya fokus komoditas yang ditetapkan sebagai komitmen nasional, dan belum optimalnya volume yang menjamin kontinyuitas.

2) Infrastruktur transportasi belum memadai baik dari segi kuantitas maupun kualitas yang antara lain karena belum adanya pelabuhan hub, belum dikelola secara terintegrasi, efektif dan efisien, serta belum efektifnya intermodal transportasi dan interkoneksi antara infrastruktur pelabuhan, pergudangan, transportasi dan wilayah hinterland.

3) Pelaku / penyedia jasa logistik masih berdaya saing rendah karena terbatasnya jaringan di antara mereka sehingga pelaku multinasional lebih dominan.

4) Teknologi Informasi dan komunikasi belum didukung oleh ketersediaan infrastruktur dan jaringan yang handal, masih terbatasnya jangkauan jaringan pelayanan non seluler, dan masih terbiasanya menggunakan sistem manual (paper based system) dalam transaksi logistik.

5) Sumberdaya manusia logistik masih memiliki kompetensi rendah yang disertai oleh belum memadainya lembaga pendidikan dan pelatihan bidang logistik.

6) Regulasi dan kebijakan masih bersifat parsial dan sektoral, yang disertai oleh masih rendahnya penegakan hukum, belum efektifnya koordinasi lintas sektoral, dan belum adanya lembaga yang menjadi integrator kegiatan logistik nasional.

Keenam unsur logistik di atas seharusnya berbentuk roda bergerigi yang jarak antar giginya sama sehingga dapat berputar dengan sinkron sebagai kegiatan logistik nasional, sebagaimana gambar di bawah. 


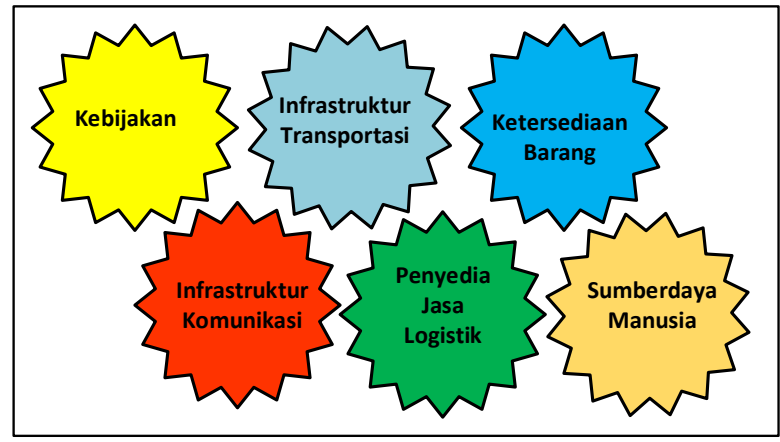

Gambar 2. Logistik Nasional Seharusnya

Diolah penyusun

Dengan memperhatikan permasalahan logistik nasional tersebut maka permasalahan dalam logistik di pelabuhan dirumuskan sebagai berikut:

1) Identifikasi sumber penciptaan nilai di pelabuhan (De Martino et al, 2010) Indonesia.

2) Bagaimana deskripsi aliran barang dan dokumen yang dapat menciptakan nilai logistik pelabuhan?

3) Mencari penyebab ketidak lancaran aliran barang di pelabuhan untuk menemukan solusi terbaiknya.

\section{KAJIAN LITERATUR}

Tulisan ini adalah literature review tentang penciptaan nilai logistik pelabuhan. Identifikasi bahwa kegiatan di pelabuhan merupakan supply chain integration telah dilaksanakan oleh Carbone and DeMartino (2003), Marlow and Paixao (2003), Paixao and Marlow (2003), Bichou and Gray (2004, 2005), Panayides (2006), Almotairi and Lumsden (2009), serta De Martino et al (2010). Penelitian-penelitian mereka dilakukan pada pelabuhan yang berbeda-beda, dengan cara yang berlainan, serta hasil yang berbeda pula. Namun demikian hasilnya dapat disimpulkan bahwa kegiatan di pelabuhan merupakan bagian dari supply chain management, interdepensi di antara pelaku di pelabuhan, serta penciptaan nilai bagi konsumen. Hasil dari literature review tersebut kemudian diterapkan untuk pelabuhan di Indonesia dalam penciptaan nilai logistik, yang merupakan hasil analisis tulisan ini.

\section{Dari Logistik ke Manajemen Matarantai Pasok}

Terminologi logistik bervariasi, salah satunya yang banyak dirujuk adalah berdasarkan pemikiran Council of Logistics Management (CLM, 1993), sebagai berikut:

"The process of planning, implementing and controlling the efficient, effective flow and storage of goods, services, and related information from point of origin to point of consumtion for the purpose of conforming to customer requirement"

Pengertian ini terkandung unsur-unsur pokok manajemen, yaitu perencanaan, implementasi dan pengawasan dalam aliran barang dan informsi secara efektifefisien dari titik asal ke titik konsumen. Esensinya adalah movement of goods 
sebagaimana gagasan Wood et al (2002), beserta informasinya, hal ini kemudian juga dirujuk oleh Perpres Nomor 26/2012. Perhatikan gambar berikut.

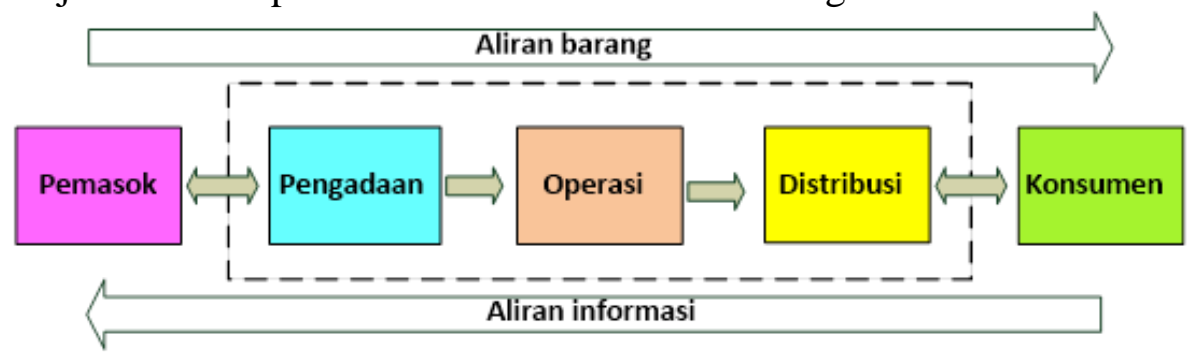

Gambar 2. Aliran Barang dan Informasi Sumber: Christopher, 2011

Pada gambar di atas nampak barang mengalir dari titik asal / pemasok, yang pemasok ini dapat beraksi aktif lebih dahulu atau bagian pengadaan yang aktif lebih dahulu. Aliran ini diteruskan ke bagian operasi, yang dalam dapat berupa bagian produksi suatu pabrik atau suatu perusahaan penyedia jasa logistik. Berikutnya ditindaklanjuti oleh bagian distribusi yang akan diteruskan ke konsumen akhir. Aliran antara bagian distribusi dengan konsumen akhir kemungkinan bagian distribusi yang aktif lebih dahulu atau sebaliknya konsumen yang aktif lebih dahulu untuk memperoleh barang tersebut. Aliran barang tersebut memerlukan transportasi, sebagai gagasan Yercan and Yildiz (2012), sebagai berikut:

"Logistics concern all the activities required for goods to be made availble to markets, with purchase, order processing, inventory management and transport among the most relevant."

Setiap aliran yang menghubungkan di antara dua bagian selalu diikuti oleh aliran informasi terhadap barang tersebut, atau sepanjang aliran barang selalu diikuti aliran informasi. Maka dapat disimpulkan bahwa aliran barang selalu didampingi oleh aliran informasi dengan arah berlawanan.

Terminologi logistik yang lebih luas diusulkan oleh Christopher (2011), sebagai berikut:

"Logistics is the process of strategically managing the procurement, movementand storage of materials, parts and finished inventory (and the related information flows) through the organisation and its marketing channels in such a way that current and future profitability are maximised through the cost-effective fulfilment of orders"

Pengertian ini menekankan adanya proses strategis-pergerakan barang-aliran informasi-distribusi-efektivitas biaya. Pengertian ini lebih lengkap daripada yang diusulkan oleh CLM (1993). Dalam manajemen, strategi adalah kompak, komprehensif dan perencanaan menyeluruh untuk meyakinkan tujuan perusahaan yang hendak dicapai (Glueck, 1980). Maka dalam tulisan ini merujuk pendapat Christopher (2011).

Manajemen rantai pasok adalah versi perkembangan dari manajemen logistik sampai awal abad 21 (Yercan and Yildis, 2012), yang meliputi proses fisik (bahan atau barang jadi) dan jasa yang terdiri dari perencanaan, pengorganisasian dan pengawasan aliran barang /jasa tersebut dari titik pemasok ke konsumen sebagai 
titik akhir. Dalam manajemen rantai pasok sudah memasukkan kepuasan konsumen, aliran finansial, aliran informasi scara terintegrasi dari semua pemangku kepentingan.

Fungsi pelayaran adalah menghantarkan barang dari pelabuhan asal di mana utilitasnya rendah ke pelabuhan lain yang utilitasnya tinggi (Branch, 2014). Maka aliran barang yang digerakkan oleh pelayaran tentu melalui pelabuhan, ini yang menciptakan nilai. Tujuan aliran barang adalah pemuasan keinginan konsumen (CLM, 1993; Lambert et al, 1998; Christopher, 2011), atau dalam pemasaran disebut consumer oriented. Carbone and De Martino (2003); De Martino et al (2010); Valentine and Benamara (2013), menyebutkan bahwa kegiatan pelabuhan sebagai penciptaan nilai, demikian juga Robinson (2002), sedangkan Radhika (2012), menyebutkan sebagai menambah nilai.

Sekarang ship-owner tidak lagi mempunyai kekuatan ekonomi untuk menentukan pemilik barang (Valentine and Benamara, 2013). Mengapa demikian ? Konsumen adalah salah satu dari unsur "Tiga P" (Ohmae, 2002), yang harus terpenuhi agar pelabuhan mempunyai keunggulan bersaing. Perhatikan gambar di bawah ini.

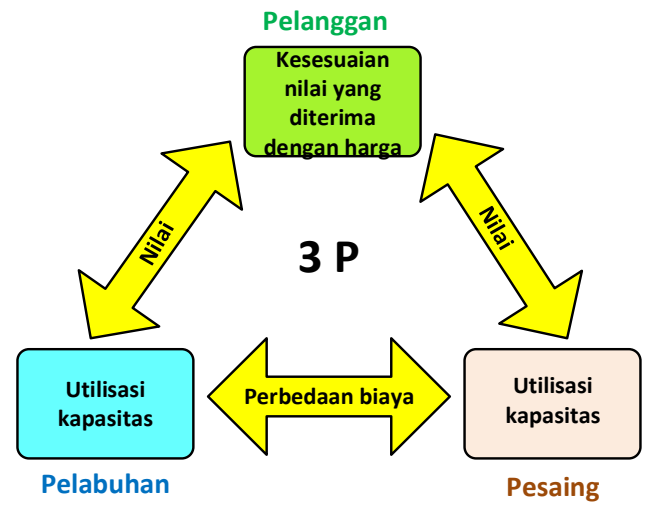

Gambar 3. Tiga $P$

Sumber: Ohmae (2002), dengan Penyesuaian

Pada gambar di atas, “Tiga P” tersebut terdiri dari perusahaan dalam hal ini adalah pelabuhan, pelanggan dalam hal ini adalah perusahaan pelayaran dan pemilik barang, serta pesaing adalah pelabuhan-pelabuhan lain ( $\mathrm{Ng}, 2012)$, terutama pelabuhan dari negara tetangga. Mekanisme ketiga unsur tersebut sebagai berikut:

1) Pelabuhan menciptakan nilai yang diperuntukkan pelanggan, dalam hal ini perusahaan pelayaran atau pemilik barang.

2) Pelanggan menerima nilai yang dijanjikan pelabuhan dengan memberi penilaian antara uang yang dikeluarkan untuk memperoleh jasa dari pelabuhan itu dengan nilai yang dirasakan. Penilaian tersebut adalah sesuai atau tidak terhadap uang yang dikeluarkannya.

3) Pesaing adalah pelabuhan lain yang juga menjual jasa yang sama dengan pelabuhan tersebut, dengan menawarkan nilai yang lebih baik, sama atau di bawah jasa yang ditawarkan pelabuhan itu pada berbagai tingkat harga. Maka pesaing bagi pelanggan merupakan opsi yang dapat dijadikan alternatif, dan 
bagi pelabuhan itu jelas merupakan pesaing walaupun dengan harga yang berbeda.

Kegiatan logistik di pelabuhan dapat menciptakan nilai jika operasinya berjalan efektif dan efisien (Lai et al, 2002; Lee and Song, 2010). Efektivitas (do the right thing), merupakan komponen kinerja vital suatu pelabuhan (Brooks and Pallis, 2008), dan efisiensi (do the thing right), merupakan isu kunci untuk pengembangan pelabuhan (Farrel, 2009). Dalam arti lebih efektif dan lebih efisien dibanding pesaingnya (Ohmae, 2002), yang hal ini berarti menciptakan keunggulan bersaing.

Christopher (2011), menyatakan tentang keunggulan bersaing sebagai hasil kegiatan logistik sebagai berikut:

"It is only in the recent past that business organisations have come to recognise the vital impact that logistics management can have in the achievement of competitive advantage"

Pentingnya pelabuhan melaksanakan manajemen logistik agar memperoleh keunggulan bersaing melalui kinerjanya di antara pelabuhan-pelabuhan lain adalah keniscayaan. Radhika (2012), menyatakan bahwa keunggulan bersaing pelabuhan ditentukan oleh efisiensi penanganan muatan dan tingkat keterkaitan dalam rantai pasok, pendapat ini menguatkan gagasan Robinson (2002). Pandangan global sekarang ini persaingan ketat bukan lagi antar perusahaan, namun antar keunggulan rantai pasoknya (Chistopher, 2011). Sementara keunggulan rantai pasok di pelabuhan ditentukan dari produktivitas pelabuhan tersebut (Lihat misalnya Brooks and Pallis, 2008 berargumen bahwa kinerja suatu pelabuhan ditentukan dari perbandingan input dan output pelabuhan tersebut). Maka syarat pelabuhan agar mempunyai daya saing harus mempunyai efisiensi dan sekaligus merupakan matarantai pasok efektif.

Perkembangan selanjutnya adalah dari logistik ke matarantai pasok atau supply chain (SC). Walaupun Lambert et al (1998), memberikan nama antara logistik dan SC dapat saling menggantikan, namun banyak pemikir lain yang memberi pemilahan namun tidak dapat dipisahkan di antara kedua nama tersebut. Berikut gagasan perkembangan tersebut.

Logistik pada dasarnya berorientasi perencanaan dan kerangka kerja yang berusaha untuk menciptakan perencanaan tunggal terkait aliran barang dan informasi melalui bisnis. Sementara SC dibangun atas kerangka kerja logistik tersebut dan berusaha untuk mengkoordinasikan proses di antara entitas yang terlibat. Christopher (2011), mendefinisikan manajemen matarantai pasok sebagai berikut:

"The management of upstream and downstream relationships with suppliers and customers in order to deliver superior customer value at less cost to the supply chain as a whole"

Fokus manajemen matarantai pasok adalah kooperasi dan kepercayaan seluruh pemain yang terlibat dalam matarantai pasok. Relationships di antara mereka dengan maksud menghasilan keuntungan secara keseluruhan yang lebih baik daripada mereka bekerja sendiri-sendiri. Sebagai perbandingan, Harisson and Van Hoek (2008), memberikan terminologi rantai pasok sebagai berikut: 
"A supply chain is a network of partners who collectively convert a basic commodity (upstream) into a finished product (downstream) that is valued by end-customers, and who manage returns at each stage"

Penekanan pada terminnologi tersebut adalah jaringan kerja di antara pelaku rantai pasok, baik jaringan ke atas / pemsok maupun ke bawah / konsumen. Baik Christopher (2011) maupun Harisson and Van Hoek (2008), juga sama-sama penyampaian nilai pada konsumen. Jaringan kerja dimaksud tergantung pada kekuatan hubungan di antara mereka sebagai rantai serta kinreja internal masingmasing (Yercan and Yildis, 2012).

Lambert et al (1998) dan Lambert and Cooper (2000), menggambarkan manajemen rantai pasok sebagaimana gambar di bawah.

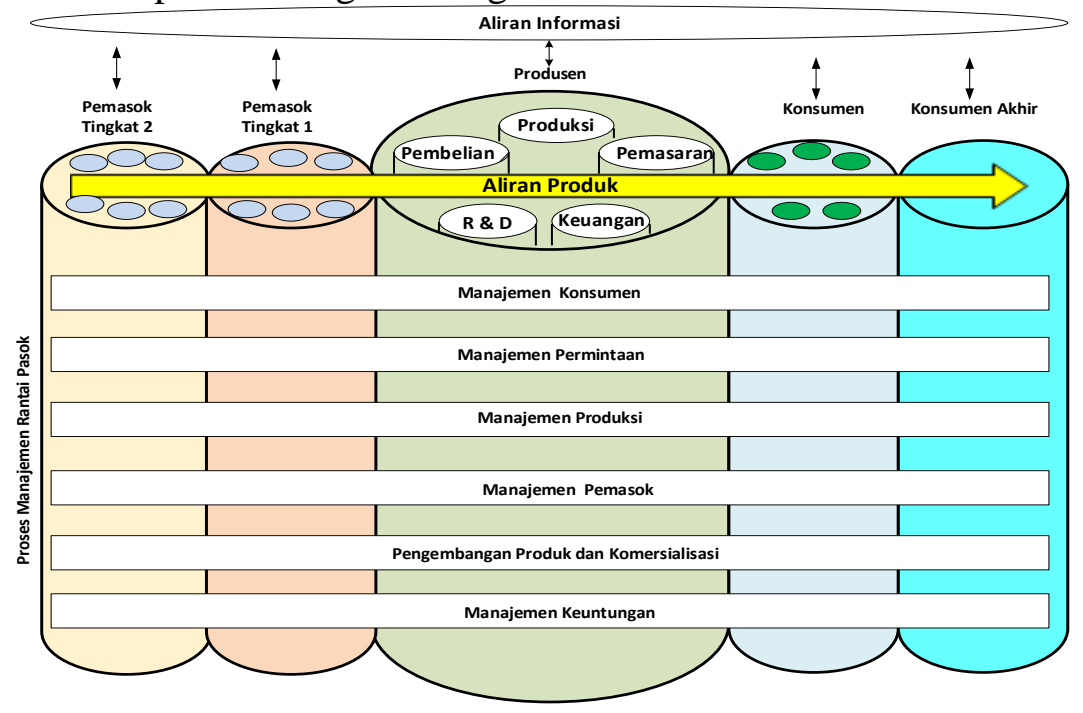

Gambar 4. Manajemen Rantai Pasok, dengan Penyesuaian Sumber: Lambert et al (1998); Lambert and Cooper (2000)

Pada gambar di atas diasumsikan bahwa pelaku rantai pasok adalah produsen (pabrik), nampak ada 2 (dua) aliran utama, yaitu aliran produk dan aliran informasi. Aliran produk tersebut meliputi: hubungan dengan pemasok tingkat 2 yang berupa site plant bahan baku, yang dilanjutkan ke pemasok tingkat 1 sebagai pemasok antara dengan menge-pool bahan baku dari pemasok tingkat 2 (yang mungkin sumbernya dapat lebih dari 1 sumber), hubungan ke dengan pemasok tingkat 2 dan dengan pemasok tingkat 1 disebut hubungan ke atas (upstream). Kemudian berlanjut ke produsen untuk mengolah bahan mentah menjadi barang jadi. Berikutnya setelah barang jadi dihantarkan ke konsumen (dalam hal ini konsumen antara, misalnya distributor atau toko), kemudian berlanjut ke konsumen akhir yang menggunakan produk tersebut. Hubungan dengan konsumen antara dan dengan konsumen akhir disebut hubungan ke bawah (downstream).

Pada internal produsen bagian yang terlibat adalah bagian pembelian bahan baku, bagian produksi, bagian pemasaran, bagian reseach and development $(R D)$ serta bagian keuangan. Untuk mewujudkan efektivitas hubungan sejak dari pemasok tingkat 2 sampai ke konsumen akhir diperlukan manajemen konsumen, manajemen permintaan, manajemen produksi, manajemen pemasok, 
pengembangan produk-komersialisasi, serta manajemen keuntungan, yang kesemuanya memerlukan informasi yang memadai.

\section{Logistik Maritim}

Kegiatan pelayaran terdiri dari 2 (dua) kegiatan utama, yaitu kegitan pelabuhan (port side) dan kegiatan kapal (ship side), yang keduanya tidak dapat dipisah (Cullinane, 2005; Cullinane and Talley, 2006; Radhika, 2012). Sedangkan di luar itu merupakan bisnis penunjang ekonomi pelayaran. Menurut Song and Panayides (2012), logistik maritim termasuk disiplin baru yang dikembangkan dari kegiatan kapal dan kegiatan pelabuhan. Kapal tidak dapat melakukan operasi tanpa adanya fasilitas pelabuhan (Branch, 2014), dan pelabuhan tanpa ada kapal yang singgah di situ berarti mati. Pelabuhan mengkoordinir kapal dan kegiatan pendukung pelayaran lainnya, sedangkan kapal menyediakan jasa transportasi laut. Maka pelabuhan dan kapal membentuk logistik maritim. Oleh karenanya antara ship side dengan port side tidak dapat dipisahkan dalam cakupan logistik maritim. Untuk jelasnya perhatikan gambar berikut.

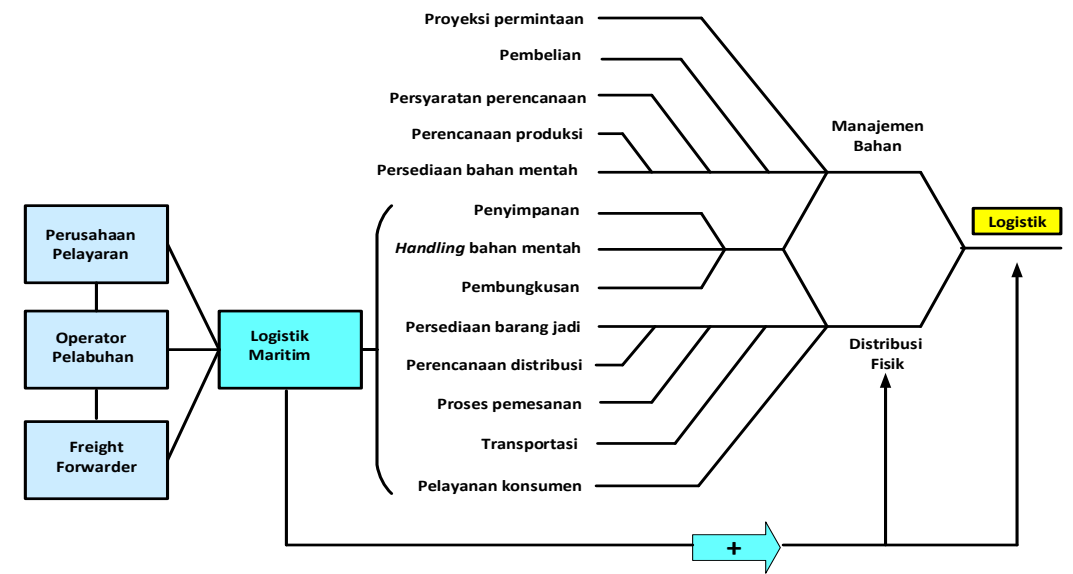

Gambar 5. Logistik Maritim

Sumber: Lee and Song, 2010

Pada gambar di atas nampak bahwa logistik maritim terdiri dari 3 (tiga) pemeran utama, yaitu:

3.2.1. Perusahaan pelayaran (ship side) yang menyediakan kapal / jasa pengangkutan laut, baik berbentuk agen, cabang, atau induk.

3.2.2. Operator pelabuhan (port side) yang menyediakan jasa pelabuhan untuk aktivitas kapal dalam melakukan bongkar-muat.

3.2.3. Freight forwarder, yaitu mediator antara pemilik barang dengan perusahaan pelayaran dan operator pelabuhan untuk memudahkan pelaksanaan pengapalan atau peneriman muatan.

Ketiga pemeran utama di atas membentuk maritim logistik, dan selanjutnya maritim logistik ini menambah logistik secara keseluruhan atau logistik nasional. Walaupun dalam cakupan tulisan ini fokusnya pada sisi pelabuhan namun ship side tetap tidak dapat ditinggalkan.

Carbone and De Martino (2003), menggagas tentang manajemen rantai pasok di pelabuhan seperti dinyatakan sebagai berikut: the aim of this work is to 
analyse how and if port operators can face the challenge of higher integration. Bahwa tantangan dalam manajemen rantai pasok pada pelabuhan adalah integrasi yang lebih baik di antara entitas di dalamnya. Integrasi banyak kegiatan dan banyak entitas di pelabuhan akan menaikkan kelincahan, yang hal ini sangat diharapkan oleh konsumen pelabuhan. Menurut Christoper (2000), kelincahan pelabuhan dapat terwujud jika dapat memadukan 4 faktor : kepekaan terhadap pasar, menunjukkan fungsi pelabuhan yang sebenarnya, dapat mengintegrasikan berbagai kegiatan, dan berbasis jaringan. Perhatikan gambar berikut.

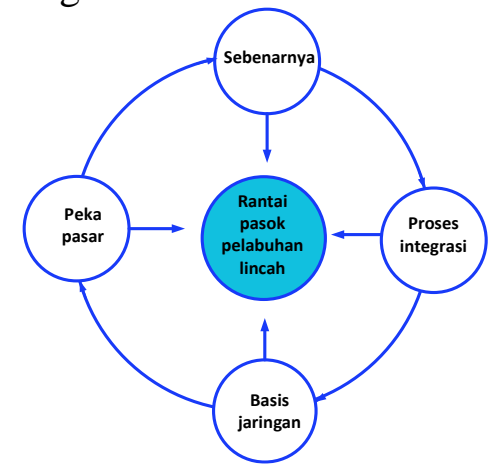

Gambar 6. Rantai Pasok Pelabuhan Lincah

Sumber: Christopher (2000), dengan Penyesuaian

Pada gambar di atas nampak bahwa keempat faktor tersebut bekerja dengan hukum sebab-akibat, yang semuanya bermuara pada rantai pasok pelabuhan yang lincah.

Martino et al (2010), pada IMP Conference di Budapest Hungaria menyatakan bahwa, the port as a network of actors, resources and activities. Di pelabuhan banyak sumberdaya yang menciptakan aktivitas dari banyak pelaku, oleh karenanya peran pelabuhan sebagai integrator agar kegiatan arus barang dapat berjalan dengan baik. Pada gambar No. 2 di atas unsur-unsur logistik tersebut masing-masing berbentuk roda bergerigi yang sesuai di antara mereka sehingga dapat berputar secara sinkron.

\section{METODE}

Metode yang digunakan: Pertama, me-review jurnal-jurnal tentang supply chain integration yang muaranya ke penciptaan nilai bagi konsumen. Kedua, melacak jurnal-jurnal yang membahas perkembangan dari cakupan logistik ke manajmen matarantai pasok untuk mengethaui arah ke penciptaan nilai bagi konsumen, khususnya konsumen barang yang diangkaut melalui laut. Terakhir, nilai yang diciptakan dari logistik pelabuhan di Indonesia.

\section{HASIL DAN PEMBAHASAN}

\section{Pelaku Logistik di Pelabuhan Indonesia}

Pelaku logistik di pelabuhan Indonesia sangat banyak. Perhatikan gambar di bawah yang dapat mewakili fungsi logistik di pelabuhan Indonesia pada umumnya. 


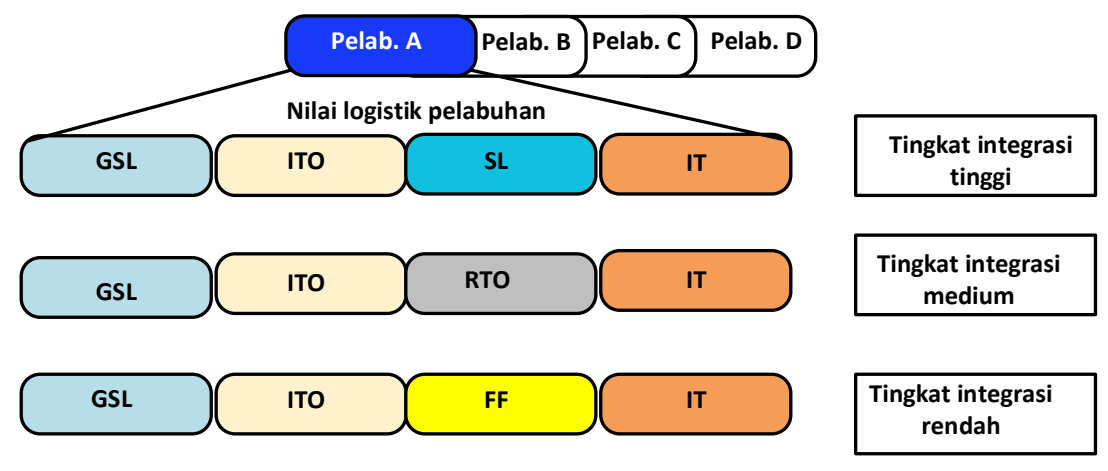

Gambar 6. Pelaku Logistik di Pelabuhan Indoneasia Sumber: Vitsounis and Pallis (2012), dengan Penyesuaian

Pada gambar di atas, nampak bahwa di pelabuhan ada 6 pelaku logistik. Masing-masing adalah :

1. Global Shipping Line (GSL), adalah perusahaan pelayaran yang beroperasi pada jalur ocean going (pelayaran internasional) yang mempunyai agen / cabang pada Pelabuhan A. Misalnya Marsk Line yang mempunyai agen di Pelabuhan Tanjung Priok Jakarta. Nilai yang diciptakan adalah "jasa inti” yaitu angkutan laut.

2. Iternational Terminal Operator (ITO), adalah perusahaan yang bergerak pada pengoperasian terminal tertentu di Pelabuhan A. Misalnya PT. Jakarta International Container Terminal (PT. JICT) yang berdiri sejak 1999, mayoritas sahamnya (51\%) dimiliki oleh Hutchison Port Holding Group (HPH Group) dan 48,9\% dimiliki oleh Koperasi Pegawai Maritim PT. Pelindo II Cabang Tanjung Priok. Maka PT. JICT adalah termasuk ITO. Nilai yang diciptakan adalah pergerakan barang di terminal PT. JICT.

3. Shipping Line $(S L)$ adalah perusahaan pelayaran yang beroperasi pada jalur nasional, misalnya PT. Meratus yang beroperasi secara nasional dan mempunyai kantor cabang di Pelabuhan A, misalnya Pelabuhan Tanjung Priok Jakarta. Nilai logistik yang diciptakan adalah memasok muatan yang akan diekpor oleh eksportir tertentu melaui PT. JICT dan pelaku angkutan lautnya Marsk Line.

4. Inland Terminal (IL), adalah perusahaan yang beroperasi pada port side, misalnya perusahaan pergudangan atau depo petikemas. Nilai logistik yang diciptakan adalah jasa penyimpanan muatan.

5. Rail Terminal Operator (RTO) adalah terminal di Pelabuhan A yang mengoperasikan terintegrasi dengan angkutan kereta api. Contoh Pelabuhan Tanjung Priok (dulu) dioperasikan terintegrasi dengan angkukan kereta api agar diperoleh efisiensi logistik, namun sekarang tidak sudah tidak lagi mengoperasikan angkutan kereta api dengan berbagai alasan. Nilai logistik yang diciptakan adalah efisiensi pengangkutan darat.

6. Freight Forwarder $(F F)$, adalah perusahaan jasa yang bertindak mewakili pengirim barang atau penerima barang yang menggunakan / ikut beroperasi di Pelabuhan A, yang tidak memiliki kapal. Perusahaan jenis ini termasuk perusahaan yang "murni” sebagai perusahaan jasa logistik. Nilai logistik yang 
diciptakan adalah memudahkan pengurusan pengiriman barang melalui pelabuhan.

Dalam beberapa kasus GSL juga berperan sebagai ITO jika perusahaan pelayaran ocean going tersebut juga mempunyai saham dalam terminal operator. Hubungan di antara kelima jenis perusahaan tergantung jenjang tingkat integrasinya (Vitsounis and Pallis, 2012), yang dalam hal ini ada 3 (tiga) tingkat integrasi. Masing-masing adalah sebagai berikut.

1. Tingkat integrasi rendah, integrasi pergerakan barang di pelabuhan melibatkan GSL- ITO-FF-IT. Barang yang datang/pergi di pelabuhan untuk tujuan diimpor/diekspor yang diangkut oleh GSL kemudian diteruskan ke ITO sebagai entitas yang mengoperasikan terminal untuk barang ekspor-impor. Barang tersebut jika memerlukan penumpukan memerlukan entitas IT dengan melalui FF sebagai wakil eksportir/importir. Dalam logistik maritim ada 3 (tiga) pelaku pokok, yaitu perusahaan pelayaran (GSL dan SL), terminal operator, serta freight forwarder (Lee and Song, 2010).

2. Tingkat integrasi medium, integrasi pergerakan barang mulai datang/pergi untuk impor-ekspor dikoordinir oleh GSL sebagai entitas logistik era 2000an, yang mengangkut barang tidak lagi dengan batasan port to port namun door to door (Cullinane and Khanna, 2000; World Bank Technical Team, 2005; Stopford, 2009). Artinya barang tersebut sejak berasal dari gudang pengirim di luar negeri, pengangkutan darat (trucking), pengapalan, cargo hanling di ITO, angkutan ke luar pelabuhan melalui operator kereta api atau jika barang tersebut memerlukan penumpukan, semuanya dikoordinir oleh GSL. Semua itu dalam rangka efisiensi logistik agar harga menjadi kompetitif (Ohmae, 2002).

3. Tingkat integrasi tinggi, pergerakan barang untuk tujuan ekspor-impor diperankan oleh SL yang beroperasi pada jalur domestik yang berfungsi sebagai angkutan pemasok kepada GSL yang berfungsi sebagai angkutan pengumpul. Oleh karenanya ITO dalam hal ini manangani barang sebagai terminal pemasok dan pengumpul barang. Pemasok dalam hubungannya dengan SL, dan pengumpul dalam hubungannya dengan GSL. Barang tersebut dapat ditangani secara truck lossing atau dalam hal-hal tertentu memerlukan IT untuk penumpukan. Argumentasinya bahwa GSL mempunyai kapasitas lebih besar daripada SL. Agar GSL dapat beroperasi secara ekonomis maka perlu dipasok oleh SL sampai utilitas ruangan kapalnya mencapai tingkat ekonom is atau bahkah penuh.

Hubungan di antara kelima entitas di pelabuhan menciptakan nilai yang diterima (dinikmati) di antara mereka, yang akhirnya akan dinikmati juga oleh konsumen akhir ketika barang yang diterimanta tepat kualitas, tepat jumlah, tepat harga, dan tepat waktu. Kesemuanya itu merupakan nilai yang diciptakan oleh logistik pelabuhan secara terintegrasi. Hal ini akan menghasilkan nilai lebih tinggi jika di antara entitas tersebut semakin terintegrasi. Jika mereka melayani secara parsial sesuai visi entitas individual akan menghasilkan nilai logisti pelabuhan lebih rendah daripada jika melayani secara terintegrasi keseluruhan.

Pada setiap pelabuhan, misalnya Pelabuhan A mempunyai tingkat keunggulan bersaing melalui tingkat integrasi yang berbeda-beda, misalnya dengan Pelabuhan B, Pelabuhan C, Pelabuhan D dan seterusnya. dan seterusnya. Semakin 
terintegrasi semakin baik efisiensi logistiknya. Hal ini sesuai ciri persaingan logistik sekarang, yang mana persaingan antar pelabuhan ditentukan oleh nilai rantai pasok (Vitsounis and Pallis, 2012; Ng, 2012). Pelabuhan di Indonesia mempunyai tingkat integrasi yang berbeda-beda, di Pelabuhan Kelas Utama mempunyai integrasi yang lebih tinggi daripada pada Pelabuhan Kelas II, apalagi pada kelas lebih rendah.

\section{Penciptaan Nilai Logistik Pelabuhan melalui Ketergantungan}

Pencipataan nilai logistik pelabuhan dapat terwujud karena input-output di antara entitas di pelabuhan yang kompleks. Hubungan mereka menciptakan ketergantungan (interdependencies), yang hasilnya berupa kikerja logistik pelabuhan. Hubungan ketergantungan berupa ketergantungan teknis-fisik dan ketergantungan administratif (Hakansson and Persson, 2004; Vitsounis and Pallis, 2012). Adapun jenis ketergantungan tersebut ada 3 (tiga), yaitu ketergantungan serial, ketergantungan dikumpulkan, dan ketergantungan pertukaran timbal balik (Hakansson and Persson, 2004).

\section{Ketergantungan Serial}

Penciptaan nilai logistik pelabuhan melalui pergerakan barang ketergantungan serial (berseri) dapat dijelaskan sbagai beikut. Jasa yang dihasilkan dati satu aktor di pelabuhan (output) merupakan input bagi aktor pelabuhan yang lain. Ketergantungan di antara mereka menciptakan/meningkatkan nilai ketika aliran serial dapat berjalan efektif. Pada gambar berikut menjelaskan hubungan di antara masing-masing aktor di pelabuhan.

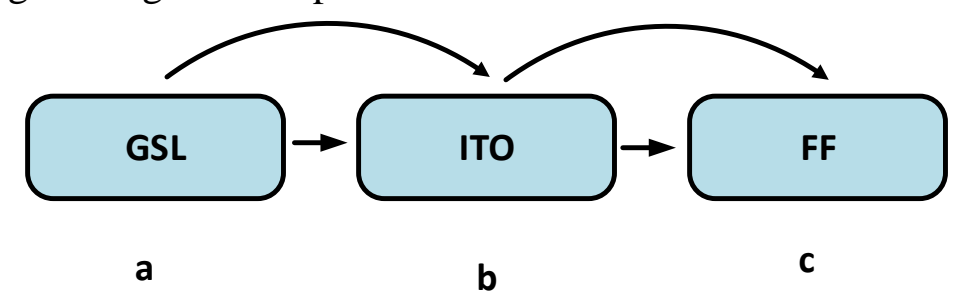

Gambar 7. Ketergantungan Serial

Sumber: Vitsounis and Pallis, 2012

Pada gambar di atas, GSL, ITO, dan FF adalah perusahaan yang berbeda bisnisnya, namun menciptakan nilai logistik pelabuhan jika aliran barang mengalir secara serial. Oputput GSL berupa muatan impor (notasi a) merupakan input bagi ITO yang menghasilkan output (notasi b). Seterusnya hasil ITO menjadi masukan bagi FF yang mengasilkan jasa (notasi c). Seterusnya hasil dari FF ini menjadi nilai tambah bagi konsumen akhir, ketika barang yang diterimanya dalam keadaan tepat kualitas, tepat jumlah, tepat harga, dan tepat waktu. Itulah nilai logistik pelabuhan melalui pergerakan barang serial interdepensi.

\section{Ketergantungan Dikumpulkan}

Penciptaan nilai logistik pelabuhan melalui pergerakan barang dikumpulkan adalah sebagaimana pada gambar berikut. 


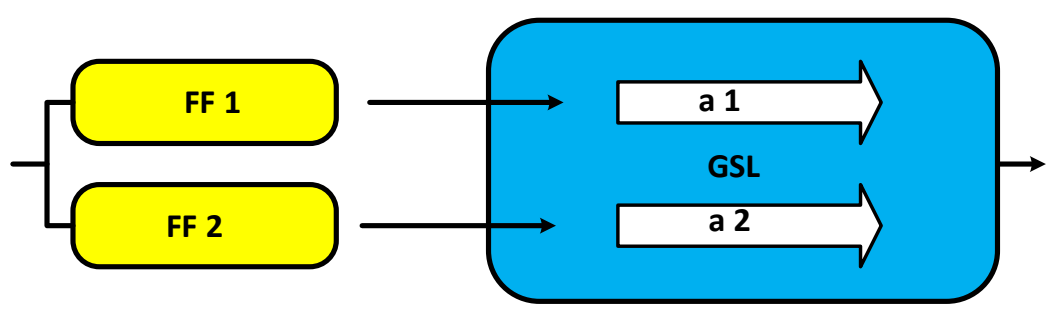

Gambar 8. Ketergantungan Dikumpulkan

Sumber: Vitsounis and Pallis (2012), dengan Penyesuaian

Pergerakan barang pada ketergantungan dikumpulkan dapat dijelaskan sebagai berikut. Kedua aktivitas yaitu freight forwarder 1 dan freight forwarder 2 adalah pelaku logistik pihak ketiga (third party logistics) berbeda yang sama-sama menngerjakan aktivitas untuk GSL. Mengingat bahwa GSL adalah perusahan pelayaran dengan skala ekonomi tinggi atau megacarrier (Robinson, 2002), maka jika muatan hanya berasal dari satu freight forwarding saja ruang kapal belum cukup terisi sehingga dalam operasi pelayaran masih rugi. Untuk menaikkan utilitas ruang kapal maka GSL harus menjalain dengan lebih dari satu freight forwarder, yang umunya adalah pelaku logistik pihak ketiga. Hubungan antara FF1 dengan FF2 adalah tidak langsung, karena harus melalui GSL untuk mengetahui tingkat utilitas yang sudah dicapai, baik pada tingkat a1 maupun tingkat a2.

\section{Ketergantungan Pertukaran Timbal-Balik}

Penciptaan nilai logistik pelabuhan melalui pergerakan barang pertukaran timbal-balik berarti di sini terjadi pertukaran input dan output di antara dua entitas di pelabuhan. Untuk jelasnya lihat gambar di bawah.

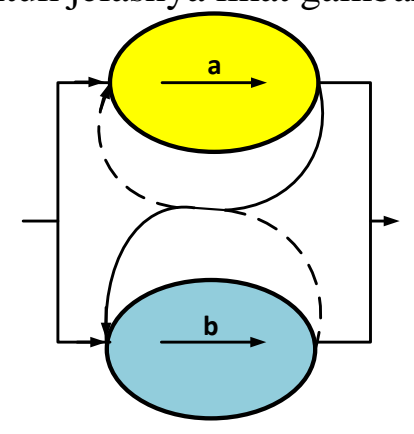

Gambar 9. Ketergantungan Pertukaran Timbal-Balik

Sumber: Hakansson and Persson, 2004

Pada gambar di atas nampak aktivitas a melayani aktivitas b, dan pada waktu yang sama aktivitas a tergantung input dari aktivitas b. Karakteristik pertukaran timbal-balik adalah ketika pada waktu yang sama kedua aktivitas harus berubah bersamaan secara sinkron. Jika salah satu aktivitas berubah sementara yang lain tidak, jelas akan menghentikan aliran barang di pelabuhan. Karakteristik ini dapat terjadi karena aktivitas a dan aktivitas $b$ adalah bersifat komplementer dalam pergerakan barang di pelabuhan secara menyeluruh. 
Permasalahan yang riil hampir di seluruh pelabuhan di Indonesia adalah ketidak sinkronan antara kegiatan di daerah penyangga (hinterland) dengan sistim yang disediakan di terminal. Di JICT misalnya, dalam 1 jam dapat memproses 30 petikemas ukuran 20" sementara ketersediaan proses di luar dalam jumlah pemasukan dan jumlah pengeluaran tidak seimbang. Jika jumlah pemasukan dalam waktu yang sama 40 unit sementara jumlah pengeluaran hanya 30 unit maka terjadi penumpukan terjadi 10 unit setiap jam. Ini jelas mengganggu sinkronisasi logistik pelabuhan secara keseluruhan.

\section{SIMPULAN}

\section{Kesimpulan}

1. Indonesia masih menghadapi masalah logistik nasional berupa kebijakan, infrastruktur transportasi, ketersediaan barang, sumberdaya penyedia jasa logistik.

2. Sumber penciptaan nilai di pelabuhan melalui nilai tambah yang diciptakan oleh masing-masing pelaku logistik di pelabuhan

3. Aliran barang dan dokumen di pelabuhan dapat berseri, dikumpulkan lebih dulu, atau timbal-balik.

4. Kegiatan masing - masing pelaku di pelabuhan semakin terintegrasi semakin baik.

5. Belum sinkronnya aliran barang (petikemas) yang masuk ke pelabuhan dengan yang keluar.

\section{Saran}

1. Menciptakan ketersediaan barang (kargo) di masing-masing pelabuhan.

2. Sinkronisasi aliran barang masuk dengan yang keluar pelabuhan.

3. Kebijakan logistik nasional yang kompak dari masing-masing sektor / kementerian

4. Peningkatan wawasan dan ketrampilan logistik sumberdaya manusia penyedia jasa logistik.

\section{DAFTAR PUSTAKA}

Almotairi, B. and Lumsden, K. (2009). Port logistics platform integration in supply cahin management. International Journal of Shipping andf Transport Logistics. Vol. 1 No. 2, pp. 194-210.

Bichou, K. and Gray, R. (2004). A logistics and supply chain management approach to port performance measurement. Maritime Policy and Management. Vol. 31 No. 1, pp. 47-67.

Bichou, K. and Gray, R. (2005). A critical review of conventional terminology for classifying seaports. Trasportation Reaseach Part A. Vol. 39 No. 1, pp. 75-92.

Branch, A.E. (2014). Elements of Shipping. $9^{\text {th }}$ Ed. Routledge, London.

Brooks, M.R. and Pallis, A.A. (2008). Assesing port governance models: process and performance components. Maritime Policy and Management. Vol. 35 No. 4, pp. 411-432. 
Carbone , V. and DeMartino, M. (2003). The canging role of port in supply chain management: an empirical analysis. Maritime Policy and Management. Vol. 30 No. 4, pp. 303-306.

Christopher, M. (2000). The agile supply chain: competing in volatile market. Industrial Marketing Management. Vol. 29 No. 1, pp. 37- 44.

Christopher, M. (2011). Logistics and Supply Chain Management. Prentice Hall, Harlow.

Cullinane, K. and Khanna, M. (2000). Economies of scale in large containerships: optimal size and geographical implications. Journal of Transport Geography. Vol 8, pp. 181-195.

Cullinane, K. (2005). Editorial: key themes in shipping economics reseach. In Cullinane, K. (Ed). Reseach in Transportation Economics. Vol. 12 Issue 1, pp. $1-17$.

Cullinane, K. and Talley, W.K. (2006). Introduction. In Cullinane, K. and Talley, W.K. (Eds). Reseach in Transportation Economics. Vol. 16 Issue 1, pp. 1-10.

De Martino, M., Morvillo, A., and Marasco, A. (2010). Value creation within port supply network: methodoligal issues. Paper Presented at 26th IMP Conference, 2-4 September 2010, Budapest, Hungary.

Ferrari, C., Parola, F, and Morchio, E. (2006). Southern European port and the spatial distribution of EDCs. Journal of Maritime Economics and Logistics. Vol. 8 No. 1, pp. 60-81.

Glueck, W.F. (1980). Business Policy and Strategic Management. 3th Edition. Mcgraw-Hill, New York.

Greenwood, R. and Hanson, S.G. (2015).Waves in shipping prices and investment.The Quarterly Journal of Economics. Vol. 130 No. 1, pp. 563-568.

Hakansson, H. and Persson, G. (2004). Supply chain management: the logic of supply chains and networks. The International Journal of Logistics Management. Vol. 15 No. 1, pp. 11- 26.

Harisson, A. and Van Hoek, R. (2008). Logistics Management and Strategy. 3rd Edition. Prentice Hall, Harlow.

Lai, K.H., Ngai, E.W.T. and Cheng ,T,C.E. (2002). Measures for evaluating supply chain performance in transport logistics. Transport Reseach Part E. Vol. 38 No. 7, pp. 439-456.

Lambert, D.M., Stock, J. R., Ellram, L .M. (1998). Fundamentals of Logistic Management. Mc Graw-Hill, Boston.

Lambert, D.M. and Cooper, M. C. (2000). Issues in supply chain management. Industrial Marketing Management. Vol. 29, pp. 65-83.

Lee, E.S. and Song, D.W. (2010). Knowledge management for maritime logistics value: discussing conceptual issues. Maritime Policy and Management. Vol. 37 No. 6, pp. 226-242).

Marlow, P.B. and Paixao, A.C. (2003). Measuring port performance. International Journal of Transport Management. Vol 1 No. 4, pp. 189-202.

Notteboom, T.E., and Rodrigue, J.P. (2005). Port regionalization: towards a new phase in port. Maritime Policy and Management. Vol. 32 No. 3, pp. 297-313. 
Ng, A.K.Y. (2012). Container liner shipping, port development and competition. In Song, D.W. and Panayides, P.M. (Eds). Maritime Logistics - Contemporary Issues. Emerald, United Kingdom, pp. 5 - 27.

Ohmae, K. (2002). The Mind of the Strategist: The Art of the Japanese Business. Mc-GrawHill Education (India) Pvt. Limited.

Paixao, A.C. and Marlow, P.B. (2003). Fourth generation ports; a question of agility ? International Journal of Physical Distribution and Logistics Management. Vol. 33 No. 4, pp. 355-376.

Panayides, P.M. (2006). Maritime logistics and global supply cahins: toward a reseach agenda. Maritime Economics and Logistics. Vol. 8 No. 1, pp. 3-18.

Radhika, A.D. (2012). The new role of seaports as integral parts of global supply chains. Excel International Journal of Multidiciplinary Management Studies. Vol. 2 Issue 4, pp. 131-144.

Robinson, R. (2002). Ports as elements in value-driven chain system: the new paradigm. Maritime Policy and Management. Vol. 29 No. 3, pp. 241-255.

Rodrigue, J.P. and Browne, M. (2010). International maritime freight transport and logistics. In Knowles, R., Shaw, J. and Docherty, I. (Eds). Transport Geographies: An Introduction. Blackwell Publishing, Oxford, pp. 1-22.

Song, D.W. and Panayides, P.M. (2008). Global supply chain and port/terminal: integration and competitiveness. Maritime Policy and Management. Vol. 53 No. 1, pp. 73-87.

Stopford, M. (2009). Maritime Economics. Third Edition. Routledge, New York.

The Council of Logistics Management. (1993). Whats it all about ?. Oak Brook, Illinois.

Valentine , V.F. and Benamara, H. (2013). Maritime transport and international trade. Maritime Policy and Management. Vol. 40 No. 3, pp. 226-242.

Vitsounis, T.K. and Pallis, A.A. (2012). Port value chains and the role of interdependencies. In Song, D.W. and Panayides, P. (Eds). Maritime LogisticsContemporary Issues. Emerald, United Kingdom, pp. 155-173.

Wood, D.F., Barone, A.P., Murphy, P.R., Wardlow, D.L. (2002). International Logistics. Second Edition. Amacom, New York.

World Bank Technical Team, (2005). The "Door to Door” Movement of Goods. Working Paper, July 5, 2005.

Yercan, F. and Yildiz, T. (2012). International maritime trade and logistics, In Song, D.W. and Panayides, P.M. (Eds). Maritime Logistics - A Complete Guide to Effective Shipping and Port Management. KoganPage, London, pp. 23-42.

Peraturan Presiden Republik Indonesia Nomor 26 Tahun 2012 tentang Cetak Biru Pengembangan Sistem Logistik Nasional. 